\title{
Problem Based Learning for Mathematics Critical Thinking Skills
}

\author{
Nur Rohmatul Aini ${ }^{1}$, Syafrimen Syafril ${ }^{1}$, Netriwati Netriwati ${ }^{1}$, Agus Pahrudin ${ }^{1}$, Titik Rahayu ${ }^{2}$ \\ ${ }^{1}$ aini.rohmatu196@gmail.com, ${ }^{1}$ syafrimen@ radenintan.ac.id, \\ ${ }^{1}$ netriwati@ radenintan.ac.id, ${ }^{1}$ agus.pahrudin@ radenintan.ac.id, ${ }^{2}$ p91583@ siswa.ukm.edu.my \\ ${ }^{1}$ Universitas Islam Negeri Raden Intan Lampung, Jl. Letkol H. Endro Suratmin, Sukarame, Bandar \\ Lampung, Indonesia \\ ${ }^{2}$ Fakulty of Education, Universiti Kebangsaan Malaysia, 43600 UKM Bangi, Selangor, Malaysia \\ *Corresponding author: syafrimen@ radenintan.ac.id
}

Tel.: +6281374576227

\begin{abstract}
This article aims to find out how to develop student's critical thinking skills through Problem Based Learning. Single-case single-side case study design is using for method this study, involve one lecture. Data were collected through observation, interviews, and analyze document. The resultz were obtained, showing that the development of mathematics critical thinking skills was carried out using the problem based learning of two component: (i) controversial issues, and (ii) active debate. Temuan penelitian ini menunjukkan bahwa problem based learning dapat dijadikan sebagai salah satu alternative untuk mengembangkan kemampuan berfikir kritis matematis mahasiswa.
\end{abstract}

Keyword: problem based learning, mathematics critical thinking skills. 


\section{A. INTRODUCTION}

One of the mathematical thinking abilities that must be owned by students is the mathematical critical thinking ability (Ratnasari \& dkk, 2018). Critical thinking is a key factor in separating those students do math from those who truly understand what they are doing. Students apply critical thinking to find the best strategy out of many possible methods to reach a solution. Critical thinking can be as much a part of a math class as learning concepts, computations, formulas, and theorems. Activities that stimulate critical thinking will also encourage students to think and speak in mathematical terms.

Critical thinking has been listed among the key components of educational objectives of many Countries (David Hitchock, 2014). The importance of developing students critical thinking skills are also presented by Uyangor and Uzel (2005) and Ismaimuza (2010), which states that critical thinking skills mathematical can assist students in mathematics problem based learning. Some of the results above the critical thinking skills mathematics (Schumacher \& Siegel, 2015) a successful major offers a program of courses to gradually and internationally leads students from basic to advanced levels of critical thinking, while encouraging creativity and excitement about mathematics.

Terdapat perbedaan kemampuan berfikir kritis mahasiswa yang baru memasuki perguruan tinggi dengan mahasiswa diatasnya (Pascarella \&Terenzini, 2006; Pithers \& Soden, 2010). Menurut Deggs, proses pembelajaran yang memberikan kesempatan untukberinteraksi melalui diskusi, tanya-jawab (open-ended), serta menulis jawaban terkonstruksi dapat mendorong kemampuan berfikir kritis mahasiswa. Justeru, pengembangan kemampuan berfikir kritis matematis melalui pendekatan problem based learning yang menjadi fokus kajian ini sesuai dengan pendekatan pembelajaran yang diterapkan. 
Problem based learning approach can shape the students thinking activities naturally and can solve the learning problem (Hasan Baharun \& Rohmatul Ummah, 2018; Rosy \& Pahlevi, 2015). Problem Based Learning lebih efektif dibandingkan pembelajaran konvensional serta berpengaruh positif terhadap kemampuan berfikir kritis mahasiswa (Asyhar, 2015), karena pemecahan masalah melalui Problem Based Learning tersebut dapat membantu dalam mengkonstruksi pengetahuan baru (Padmavathy \& Mareesh, 2013).

Permasalahan yang terjadi pada mahasiswa saat ini adalah memahami konsep matematis masih bersifat teoritis dan kurang mengembangkan kemampuan berfikir kritis dalam mempelajari matematika dasar, khususnya materi himpunan meliputi operasi, pembuktian hukum-hukum, diagram venn, dan penerapan himpunan dalam kehidupan (Netriwati, 2018; Jong Jek Siang, 2009). Materi tersebut merupakan bekal dasar mahasiswa pada pembelajaran semester berikutnya. Sehingga, kemampuan berfikir kritis sangat dibutuhkan untuk mengidentifikasi permasalahan yang ditemui dalam proses pembelajaran (Susiaty, Firdaus, \& Hodiyanto, 2017). Kajian (Fadhilah, 2016) menunjukkan bahwa mahasiswa sulit beradaptasi, berdiskusi, berkomunikasi, bekerjasama dalam kelompok, memecahkan masalah ketika diberikan pertanyaan atau umpan balik, serta belum bias memberikan kesimpulan yang tepat dalam proses pembelajaran (Putra,F.G, 2017; Akmalia, Pujiastuti, \& Setiani, 2016). Walaupun menurut (Yanti \& Syazali, 2016) proses berfikir dan kemampuan setiap individu berbeda-beda dalam memecahkan masalah matematika.

Kajian tentang pengembangan kemampuan berfikir kritis matematis yang lebih kurang sama dengan penelitian ini telah dilakukan oleh beberapa peneliti sebelumnya (Dwiyanti \& Nasrullah, 2018; Widayanti \& Subekti, 2017; Rahmawati, 2013) kajian-kajian tersebut mendapati bahwa pendekatan problem based learning menghantarkan mahasiswa lebih aktif mempresentasikan dan melakukan diskusi untuk memecahkan masalah. Terdapat juga kajian tentang pengembangan kemampuan berfikir kritis matematis yang dikaitkan dengan analisis real (Meyta Dwi Kurniasih, 2017), dan gradient pesamaan garis lurus . Kajian tentang pengembangan kemampuan berfikir kritis matematis juga dikaitkan dengan 
metode yang berbeda seperti problem posing, multiple intelligence, dan IMPROVE (Rustina, 2016; Mujib \& Mardiyah, 2017; Mujib, 2016). Secara umumnya, penelitian tersebut menggambarkan pentingnya kemampuan berfikir kritis dalam proses pembelajaran matematika. Justeru, penelitian ini coba melihat bagaimana pengembangan kemampuan berfikir kritis matematis melalui problem based learning pada mahasiswa.

\section{B. METHODOLOGY}

This study was a qualitative approach using single-case single-side case study design is using for method this study (Robbert Yin, 2013). Involve one lecture yang melaksanakan proses pengembangan kemampuan berfikir kritis matematis melalui problem based learning sebagai subjek penelitian (John W. Creswell, 2013). Observasi, wawancara, dan dokumen analisis digunakan sebagai cara pengumpulan data. Data dianalisis secara kualitatif melalui reduksi data, menyajikan data, dan menarik kesimpulan (Miles \& Huberman, 2007). Gambaran tentang pelaksanaan penelitian terlihat pada gambar 3.1 di bawah.

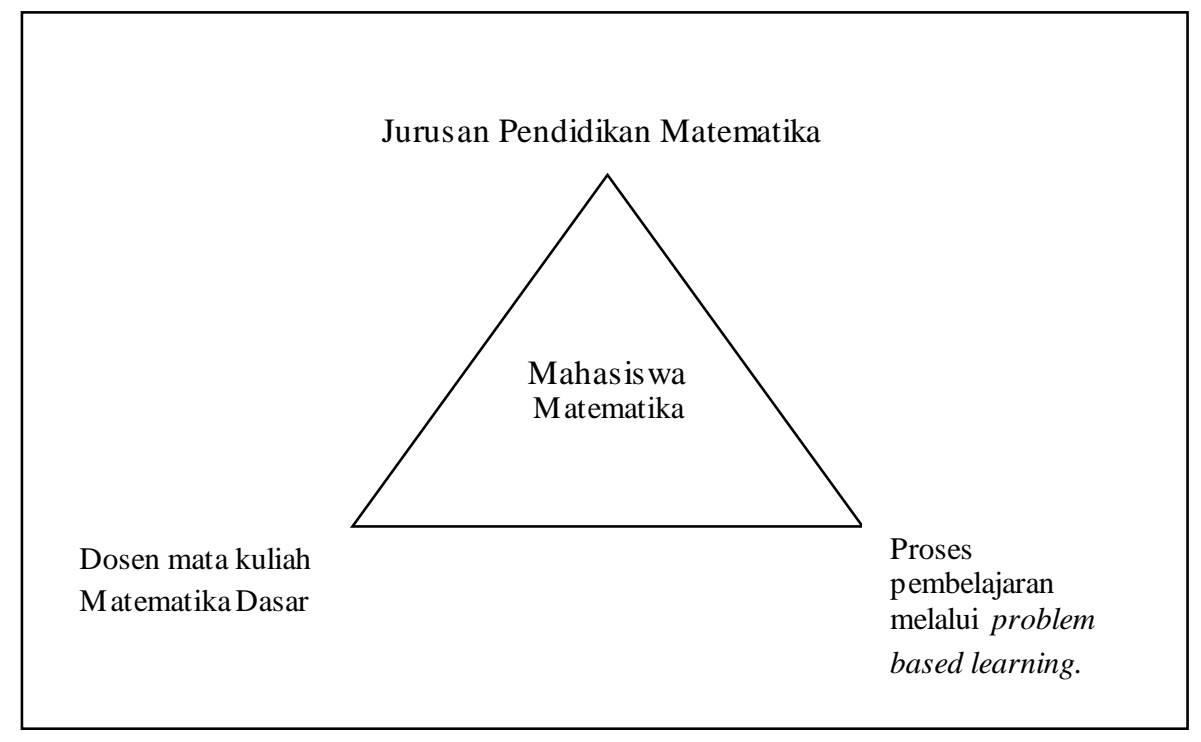

Gambar 3.1 Gambaran Tentang Pelaksanaan

Sumber: (Bogdan \& Biklen, 2007) 


\section{RESULTS}

Dari tiga cara mengumpulkan data, hasil kajian menunjukkan bahwa terdapat dua temuan yang digunakan dalam pengembangan kemampuan berfikir kritis matematis pada mahasiswa, yaitu (i) controversial issues, and (ii) active debate. Sebagaimana dipaparkan melalui berbagai symbol pada gambar berikut :

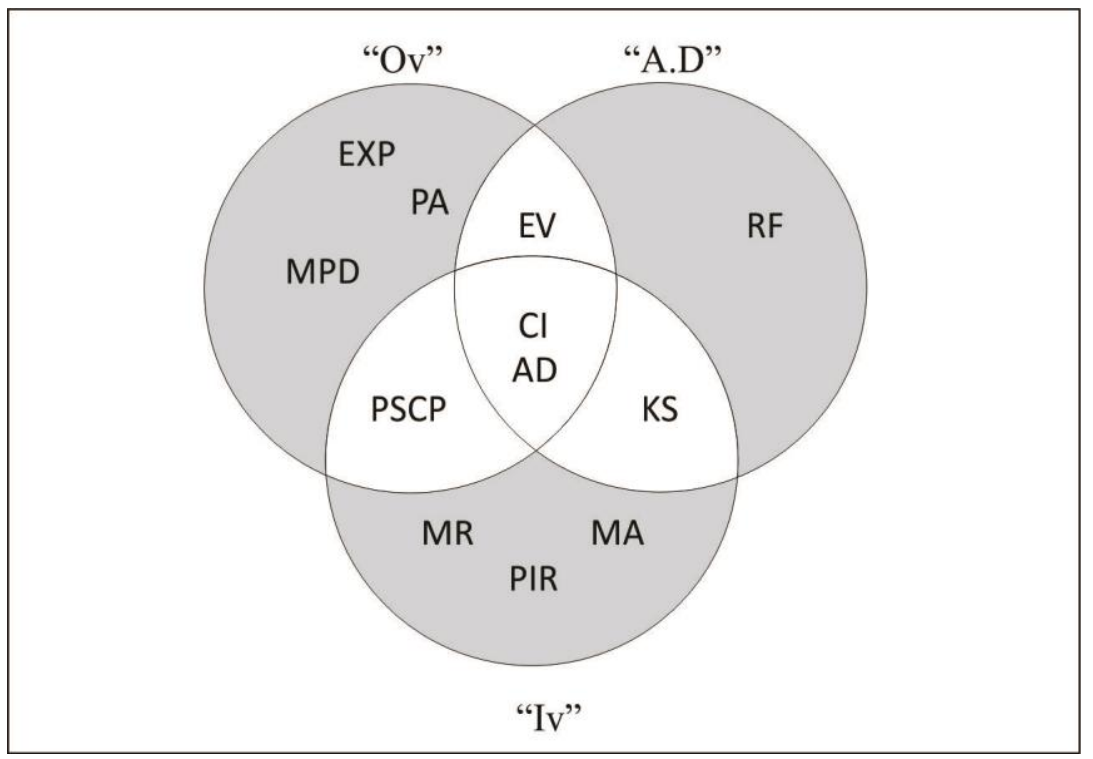

Gambar 4.1 Triangulasi Data

Source : takes the research design (John W. Creswell, 2013)

Picture Describe :

Ov : Result Observation

AD : Analysis Document

Iv : Result Interview

EXP : Explanation

RF : Accurat Refference
MR : Material Review

MPD : Monitor of progress the Discussion

MA : Material Adaption

PIR : Pour Ideas Rationally

AD : Active Debate 


$\begin{array}{llll}\text { Ev } & \text { : Evaluation } & \text { PSCP } & \begin{array}{l}\text { Provoke Students to Think } \\ \text { Critically Through Problem }\end{array} \\ \text { KS } & : \text { Kuis } & \text { CI } & : \text { Controversial Issue } \\ \text { PA } & \text { : Problem Analysis } & & \end{array}$

Controversial issues yang dimaksudkan dalam hasil kajian ini adalah pemberian ruang kepada mahasiswa untuk memecahkan permasalahan kontroversi dalam matematik melalui pemahaman masing-masing, namun permasalahan tersebut dipecahkan secara bersama dalam forum diskusi, seperti terlihat pada gambar berikut :

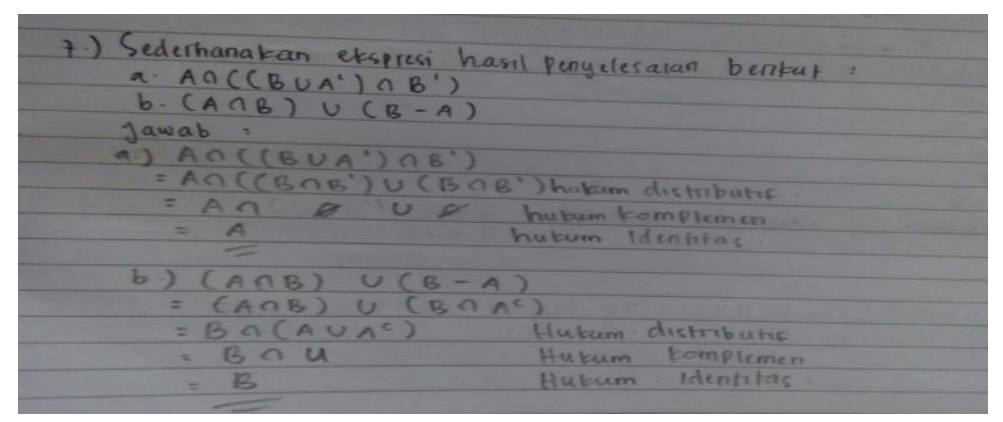

Gambar 4.2 Pemecahan Masalah Pembuktian Himpunan

Gambar tersebut memaparkan cara penyelesaian masalahan controversy oleh mahasiswa. Yang dilihat di sini adalah bagaimana cara mahasiswa menyelesaikan permasalahan matematis dalam materi himpunan yang diberi oleh dosen mengggunakan kemampuan berfikir kritis masing-masing. Sedangkan yang dimaksudkan dengan active debate adalah bagaimana mahasiswa menguraikan jawaban dengan memberikan argument dan penjelasan secara kritis dan logis yang diterima berdasar konsep matematik dalam menyelesaikan masalah yang diberikan, seperti terlihat pada gambar di bawah ini. 


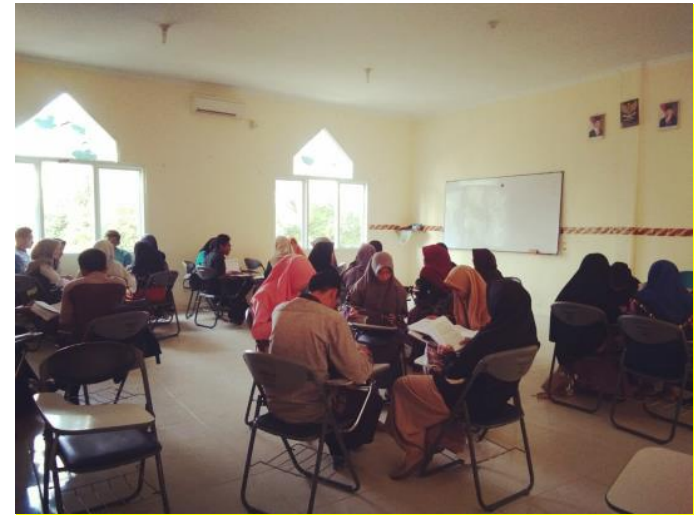

Gambar 4.3 Active Debate in Discuss

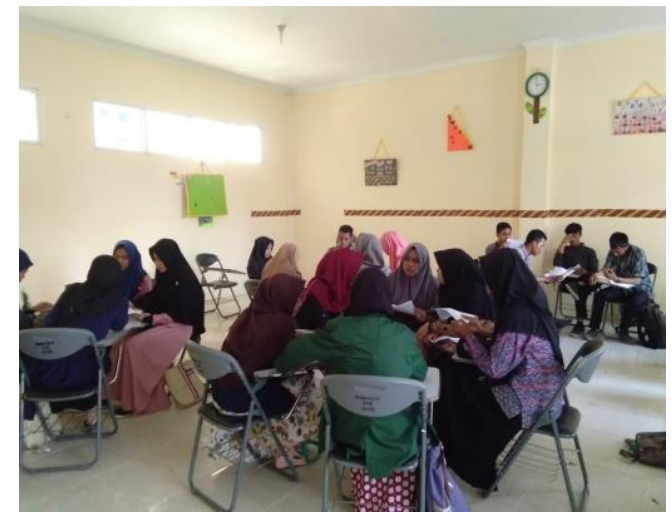

Gambar 4.4 Active Debate in Discuss

\section{DISCUSSION}

Masalah controversial merupakan isu yang diperdebatkan, dosen memberikan ruang kepada mahasiswa untuk memecahkan masalah. Mahasiswa memberikan tanggapan dan argument dalam memperdebatkan masalah tersebut. Disitulah terlihat bagaimana kemampuan berfikir kritis mereka dalam menghadapi masalah yang serius. Active debat menjadi senjata dalam menghidupkan issue controversy. Diskusi yang dilaksanakan berupa memutuskan masalah perbedaan dan silang pendapat terhadap masalah matematika akibat pemetaan konsep. Berikut contoh permasalahan materi himpunan yang bisa dijadikan issue controversy dan active debate.

"suatu kelompok mahasiswa yang terdiri dari 15 anak, 8 anak suka tennis, 9 anak suka catur, 5 anak menyukai tennis dan catur".

Untuk menjawab permasalahan tersebut, tepatnya menggunakan langkah yang terstruktur;

(i) memahami masalah, dengan cara menuliskan kembali masalah dengan kata-kata sendiri, (ii) membuat rencana atau cara untuk memecahkan masalah, (iii) menyelesaikan masalah yang ada, dengan rencana yang telah disusun, (iv) melihat kembali apa yang telah dilakukan, (v) menyimpulkan, membandingkan, mendiskusikan, menjadi issue controversy cara manakah yang lebih efisien untuk digunakan. Dalam pemecahan masalah matematika, lebih otentik jika mahasiswa mengembangkan kemampuan berfikir kritis. 
Menurut (Ebindele Ebosele Peter, 2012) mempelajari matematika dapat melatih orang disiplin berfikir kritis untuk menghadapi berbagai persoalan. Kemampuan berfikir kritis yang dikembangkan dengan pendekatan problem based learning dalam penelitian ini adalah orientasi, mengorganisasikan, membimbing, mengembangkan dan menyajikan, menganalisis dan mengevaluasi mahasiswa dalam proses penyelesaian masalah. Penjelasan (Ennis, 2011) terdapat lima indikator pengembangan kemampuan berfikir kritis matematis meliputi; (i) elementary clarification, (ii) basic support, (ii) inference, (iv) advanced clarification, (v) strategies and tactics.

Kemampuan berfikir kritis matematis dipengaruhi oleh kepercayaan diri yang dapat membentuk keyakinan tentang kemampuan untuk pantang menyerah dalam menghadapi permasalahan yang diberikan (Leonard \& Amanah, 2014). Hal ini terlihat saat proses diskusi dalam kelompok. Mahasiswa memiliki kemampuan untuk berinteraksi dengan rekan kelompoknya. Namun tentunya kemampuan mahasiswa tidaklah sama (Novtiar \& Aripin, 2017; Hidayat, Tresnawati, \& Euis Eti Rohaeti, 2017; Rochmad, 2013 ). To develop skills and character as well the civilization of dignity, in order to educate the nation, with aims to develop students potentials to become faith and fear of god almighty, noble, knowledge, creative, and responsible, the educator must be improve and given attention to students (Syafrimen, Mohd.Ishak, \& Erlina, 2017). Dalam mengembangkan kemampuan berfikir kritis harus memiliki sikap yakin dan percaya akan kemampuan sendiri, sehingga terhindar dari rasa cemas dan ragu (Rosita, 2017; Hidayat, 2017). Alternative lain dalam mengatasi hal tersebut, dosen dapat menunjukkan sikap empaty, kreativitas, dan motivasi (Syafrimen, Ishak, \& Nova Erlina, 2017). Dengan kemampuan berfikir kritis dapat memecahkan masalah, mampu menampilkan logika secara rasional dan diterima oleh orang lain. Kemudian, dapat mengetahui atau mengingat sejumlah konsep dan dapat mengungkapkan kembali dengan bahasa sendiri, menginterpretasikan dan mengaplikasikan konsep sesuai struktur cognitive (Batubara, 2017). 
Penerapan problem based learning merupakan salah satu solusi dalam pemecahan masalah. Fakta ini di dukung oleh (Safery, 2006) " the methods use in Poblem based learning and the specific skills develop, including the ability to think critically, analyze and solve complex, real-word problems, to find, evaluate, and use appropriate learning resources, and intellectual skills to become continual learnes". Melalui problem based learning, kajian tidak hanya difokuskan pada masalah, tetapi memahami konsep-konsep yang berkaitan dengan masalah dalam metode ilmiah (Sianturi, Sipayung, \& Argareta, 2018). Problem based learning dapat mengembangkan kemampuan berfikir kritis matematis secara optimal melalui proses diskusi kelompok secara sistematis. Hal ini sesuai dengan kajian yang dilakukan (Rusman, 2014). Kajian ini yang mendasari bahwa masih banyak pembelajaran matematika yang menggunakan pembelajaran secara langsung atau berpusat pada guru ataupun dosen (Jumaisyaroh \& Hasratuddin, 2015). Pendekatan yang digunakan dalam pembelajaran tentunya tidak yang sempurna. Kelebihan dan kelemahan problem based learning justeru menuntut pengembangan pembelajaran secara terus-menerus seiring dengan perkembangan tehnologi informasi yang terkadang lebih cepat dari yang kita fikirkan. Moreover, implementation of problem based learning approach and critical thinking skills begin to develop at an early age (Sungur, 2014).

\section{E. CONCLUSION}

The resultz were obtained, showing that the development of mathematics critical thinking skills was carried out using the problem based learning of two component: (i) controversial issues, and (ii) active debate. Temuan penelitian ini menunjukkan bahwa problem based learning dapat dijadikan sebagai salah satu alternative untuk mengembangkan kemampuan berfikir kritis matematis mahasiswa. Dengan demikian, temuan ini dapat diterapkan dalam pembelajaran untuk pengembangan kemampuan berfikir kritis mahasiswa. 


\section{ACKNOWLEDGEMENT}

I would like to thank Syafrimen, M.Ed, Ph.D, for his expertise, guidance, contribute, and patience throughout the process of writing this article. Thank for his willingness to read the draft article. Without his help this article would not have been possible. I would like to thank my CO-Advisor Netriwati, M.Pd, she has provided motivation, advice, and support for the researcher. Thanks for keeping me company on long walks. Then to thank Dr. Agus Pahrudin, M.Pd who has giving suggestion, contribute, and correction until the completion of this article. I thank Tarbiyah Faculty, State Islamic University Raden Intan Lampung, for the opportunity to submited this article.

\section{RUJUKAN}

Akmalia, N. N., Pujiastuti, H., \& Setiani, Y. (2016). Identifikasi Tahap Berpikir Kreatif Matematis Melalui Penerapan Model Problem Based Learning. Jurnal JPPM, 9(2), 184.

Asyhar, A. H. (2015). Aplikasi Metode Nilai Eigen Dalam Analytical Hierarchy Process Untuk Memilih Tempat Kerja. Jurnal MANTIK Pendidikan Matematika, 1(1), 7.

Batubara, I. H. (2017). Peningkatan Kemampuan Berfikir Kritis Matematis Melalui Model Pembelajaran Berbasis Masalah Berbantuan Autograph dan Geogebra di SMA Freemethodist Medan. Jurnal Wahana Inovasi, 6(1), 98.

Bogdan, \& Biklen. (2007). Qualitative Research for Education: An Introduction to theorises and Methods (5th ed.). boston: allyn bacon.

David Hitchock. (2014). Russel and Critical Thinking. Journal of the Betrand Russel Studies.

Ebindele Ebosele Peter. (2012). Critical Thinking: Essesnce for Teaching Mathematics and Mathematics Problem Solving Skills. African Journal of Mathematics and Computer Science Research, 5(3), 39.

Ennis. (2011). Goal for a Critical Thinking. University Illinois: Illinois Critical Thinking 
Project.

Fadhilah, Z. K. (2016). Pendekatan Problem Based Learning Untuk Mengembangkan Kemampuan Berfikir Kritis Mahasiswa. Jurnal Pedagogia, 5(2), 281.

Fredi Ganda Putra. (2017). Eksperimentasi Pendekatan Kontekstual Berbantuan Hands On Activity (HoA) Terhadap Kemampuan Pemecahan Masalah Matematik. Jurnal AlJabar : Pendidikan Matematika, 8(1), 75.

Hasan Baharun, \& Rohmatul Ummah. (2018). Strengthening Student's Character in Akhlaq Subject Through Problem Based Learning Model. Jurnal Tadris Keguruan Dan Ilmu Pendidikan, 3(1), 28.

Hidayat. (2017). Adversity Question dan Penalaran Kreatif Matematis Siswa SMA Dalam Pembelajaran Argument Driven Inquiry pada Materi Turunan Fungsi. Jurnal Pendidikan Matematika, 2(1), 19.

Hidayat, W., Tresnawati, \& Euis Eti Rohaeti. (2017). Kemampuan Berpikir Kritis Matematis dan Kepercayaan Diri Siswa SMA. Journal of Research in Mathematics Learning and Education, 2, 116-122.

John W. Creswell. (2013). The Case Study Approach. BMC Medical Research Methodology, 11(1), 105. https://doi.org/10.1186/1471-2288-11-100

Jong Jek Siang. (2009). Matematika Diskrit dan Aplikasinya Pada Ilmu Komputer. Yogyakarta: Andi OFFCET.

Jumaisyaroh, T., \& Hasratuddin, E. E. N. (2015). Peningkatan Kemampuan Berfikir Kritis Matematis dan Kemandirian Belajar Siswa SMP Melalui Pembelajaran Berbasis Masalah. Jurnal Mathematic Education, 5(1), 91.

Leonard, \& Amanah. (2014). Pengaruh Adversity Question dan Kemampuan Berfikir Kritis Terhadap Prestasi Belajar Matematika. Jurnal Perspektif Ilmu Pendidikan, 28(1), 5564.

Miles, \& Huberman. (2007). Qualitative Data Analysis: A Sourcebook Of New Methods. California: Sage Publications, Inc.

Mujib, \& Mardiyah. (2017). Kemampuan Berfikir Kritis Matematis Berdasarkan Multiple Intelligences. Al-Jabar:Jurnal Pendidikan Matematika, 8(2), 188. 
Netriwati. (2018). Matematika Dasar (ke-3). Lampung: Permata Net.

Novtiar, C., \& Aripin, U. (2017). Meningkatkan Kemampuan Berfikir Kritis Matematis dan Kepercayaan Diri Siswa SMP Melalui Pendekatan Open-Ended. Jurnal PRISMA, 4(2), $119-131$.

Padmavathy, \& Mareesh. (2013). Evvectiveness of Problem Based Learning In Mathematics. Journal of Education, 2(1), 49.

Ratnasari, N., \& dkk. (2018). Project Based Learning Model on the Mathematical Representation Ability. Jurnal Tadris Keguruan Dan Ilmu Pendidikan, 3(1), 49.

Robbert Yin. (2013). Qualitative Research Methodology. Journal of American, 3(1).

Rochmad. (2013). Keterampilan Berfikir Kritis \& Kreatif Dalam Pembelajaran Matematika. Seminar Presiding UNY.

Rosita. (2017). Implementasi Pembelajaran Matematika dengan Pendekatan Open-Ended Terhadap Sikap Siswa. Pasundan Journal of Research in Mathematics Learning and Education, 1(1), 13.

Rosy, B., \& Pahlevi, T. (2015). Penerapan Problem Based Learning Untuk Meningkatkan Kemampuan Berfikir Kritis dan Keterampilan Memecahkan Masalah. Prosiding Seminar Nasional UNS, 169.

Rusman. (2014). Model-Model Pembelajaran (Mengembangkan Profesionalisme Guru). Jakarta: Rajawali Pers.

Rustina, R. (2016). Efektifitas Penggunaan Model Pembelajaran Problem Posing Terhadap Peningkatan Kemampuan Berpikir Kritis Mahasiswa. JP3M (Jurnal Penelitian Pendidikan Dan Pengajaran Matematika), 2(1), 43-44.

Safery. (2006). Overview of Problem Based Learning: Definitions and Distictions. Interdisciplinary Journal of Problem Based Learning, 1(1), 10-20.

Schumacher, C. S., \& Siegel, M. J. (2015). Curriculum Guide to Majors in The Mathematical Sciences. America: The Mathematical Assosiation of America.

Sianturi, A., Sipayung, T. N., \& Argareta, M. (2018). Pengaruh Model Problem Based Learning ( PBL ) Terhadap Kemampuan Berpikir Kritis Matematis Siswa SMPN 5 Sumbul. Jurnal UNION Pendidikan Matematika, 6(1), 29-42. 
Sungur, S. (2014). Improving Achievement Through Problem-Based Learning. Journal Autumn, 40(4), 156.

Susiaty, U. D., Firdaus, M., \& Hodiyanto. (2017). Analisis Kesulitan Belajar Mahasiswa Program Studi Matematika. Jurnal SAP, 1(3), 230.

Syafrimen, Ishak, N. M., \& Nova Erlina. (2017). Six Ways to Develop Empathy of Educators. Journal of Engineering and Applied Sciences, 12(7), 1689.

Syafrimen, Mohd.Ishak, N., \& Erlina, N. (2017). Emotional Intelligence Profile of Prospective Teacher. Journal of Engineering and Applied Sciences, 12(7), 1677-1680.

Widayanti, L., \& Subekti, P. (2017). Pendekatan Problem Based Learning untuk Meningkatkan Pemahaman Konsep Mahasiswa Prodi Teknik Informatika. SINATIKA, $4,154$.

Yanti, \& Syazali. (2016). Analisis Proses Berfikir Siswa dalam Memecahkan Masalah Matematika Berdasarkan Langkah-langkah Bransford dan Stein Ditinjau dari Advertisy Question. Jurnal Al-Jabar: Pendidikan Matematika, 7(1), 65. 